\title{
Language Policy and Conflict as Learning Barriers: The Plight of Linguistic Minority Schoolchildren in Darfur, Sudan
}

\author{
Abdelrahim Hamid Mugaddam ${ }^{1, *}$, Dhahawi Salih Ali Garri ${ }^{2}$ \& Abdelbasit Alnour ${ }^{3}$ \\ ${ }^{1}$ Department of English, Jouf University, Saudi Arabia \\ ${ }^{2}$ Department of English, Nyala University, Sudan \\ ${ }^{3}$ Department of English, King Khalid University, Saudi Arabia \\ *Correspondence: Department of English, Jouf University, Saudi Arabia. E-mail: sudan_98@hotmail.com
}

Received: February 13, $2020 \quad$ Accepted: March 4, $2020 \quad$ Online Published: March 11, 2020

doi:10.5430/wje.v10n2p1 URL: https://doi.org/10.5430/wje.v10n2p1

\begin{abstract}
This paper investigates learning difficulties of the linguistic minority schoolchildren (LMS) in Darfur, Sudan, in the contexts of the current conflict and the official monolingual policy. Employing quantitative and qualitative data gathering tools, we examined how the LMS at the internally displaced persons (IDPs) camps were educationally disadvantaged due to their low proficiency in Arabic, curricula developed insensitively to their identities and cultures, and how parents and teachers perceived of teaching the children in Arabic as the sole medium of instruction. The study concluded that monolingualism in education resulted in the underachievement of the IDPs schoolchildren; the vast majority of the parents and a great number of teachers believed the children could have achieved better had the teachers used, besides Arabic, native languages in teaching; and that learning of the children could be improved if their ethnic identities and cultures were integrated in curricula. Preferences of teaching the children in Arabic among the parents were primarily attributed to the current conflict, which gave rise to the revitalisation of native languages in Darfur. The teachers' preferences thereof, however, differed - crudely traceable between one group of monolingual supporters whose perceptions were informed by their internalised state ideology of Arabicisation and another group of multilingual proponents whose viewpoints were derived from the trendy approaches favouring multilingualism in education. The findings also suggested that the government deliberately distanced itself from taking remedial interventions to mitigate the underachievement of the children with the expectation the displacement would expedite their linguistic and cultural assimilation, which have not only rendered them the most linguistically disenfranchised children in Sudan, but created the most profound de facto government language policy of its kind as well.
\end{abstract}

Keywords: language policy, conflict and displacement, academic underachievement, linguistic minority schoolchildren, multilingualism and monolingualism, Darfur (Sudan)

\section{Introduction}

Post-colonial history of most African countries is characterised by inherent linguistic hegemonies and cultural alienation, for almost in many colonised country in Africa once in its contemporary history had an officialised coloniser's language. Such situations have continued to exist until today as discourses of multilingual education and the rights of LMS to receiving instruction in mother tongue are becoming debatable issues in language policy-making. This is so as the policies of national/official language standardisation are associated with politics of elite preferences for colonial languages, their conflicting ideologies, monopoly of economic and political privileges within power wielding centres (Wright et al., 2015; Garcia, 2009; Cummins, 2000).

This paper reviews the wider spectrums of language policies in post-colonial Africa with a particular emphasis on how such policies have produced language-in-education realities unfavourable to LMS in Darfur, Sudan. Using as an example the case of the schools at IDPs camps in Darfur, the paper argues that the academic underachievement of the LMS springs from the state denial of both multilingualism and the rights to receiving instruction in mother tongue. The paper also explores the perceptions of the schoolchildren's parents and teachers towards the use of 
Arabic as a sole medium of instruction in the schools at IDPs camps.

\subsection{Conceptual Framework and Relevant Literature}

The thesis of the current paper is centred around the theory of language policy (Spolsky, 2000) which features the functions of language policy as (a) explicit ideological views of appropriate behaviours of language use; (b) individual elements of language such as pronunciation, spelling, lexical choice, grammar, racist language, and obscene language; (c) domains of language use as defined by speech communities, political or social bodies, family or by other similar entities; and (d) the complex ecological relationships, including linguistic and non-linguistic elements, variables and actors. Hence, the paper argues that language policies in Africa epitomise situations which Spolsky (ibid: ix) considers to be 'linguicentric', i.e., they are 'looked at from the point of one language only,' in the respective states.

The quest for actualising African-specific ideologies draws its legitimacy from internal motives which are often reminiscent of Africa under colonial rule; and intrinsic to that quest is the resistance of the African intelligentsias to colonial languages (Kamwangamalu, 2016; Wolff, 2017). The most workable mechanisms the post-colonial elites employed to eliminate that 'stigma' was to mesmerise the populace by mega-propagandising against the legacy of the colonial languages which were, paradoxically, officialised in many countries. In a sense, the over-decolonisation zeal appears to be moving nowhere, for it is argued that post-colonial multilingual education model-makers in their desire for building modernist nations and management of their internal differences replicated the colonisers' practices of creating ethnic identities and ideological divisions among Africans (Garcia, 2009; Evans and Cleghorn, 2012; Lin, 2015; Wolff, 2017).

While suppression of local languages was quite violent, first by the colonials and then by the neo-colonial Africans (Kamwangamalu, 2016; Babaci-Wilhite, 2015b), the recognition of multilingual education had begun to gain currency in many post-colonial African countries. Multilingualism as an established state policy has been a ubiquitous phenomenon in post-colonial Africa, but the Asmara Declaration (2000) on the linguistic rights marked the first collective platform of its kind in Africa which called for mainstreaming local languages in education. The Declaration stated that democratisation of African states should be undertaken by officialising African languages; it further emphasised that mother tongue should be used to help strengthen the linguistic and cultural values which will, in turn, make children value more their own identities. That consensual shift was driven by emerging bottom-up pressures to recognize minority linguistic rights. It was an ideology informed by the importance of factoring local languages into national unity, and embracing an indigenous African world view (Truong, 2012; May, 2008; Babaci-Wilhite, 2015b; Albaugh, 2007).

The resistance to colonial languages in Africa in essence emerged on the ground that the ex-colonial official languages would dilute the time-honoured social structures of multilingual and multicultural societies (Wolff, 2017). In consequence, the shift towards education in mother tongue in contemporary Africa has been based on the premise that local cultures can be reserved by mother tongue literacy (Holmes, 2008). With this shift, there emerged an overzealous resistance to colonial linguistic hegemony; and thus the field is charged with antipathy toward colonial languages, being voiced through coining terms exemplifying linguistic sentiments such as linguicide and linguicism by some scholars, namely Skutnabb-Kangas and Philipson (1995).

Without reiterating that there exist external factors at policy-making levels which impeded delivering effective multilingual education in Africa, it is imperative to pinpoint the parallel internal factors at instructional levels which are at play as well. These are the culture-bound barriers which can hamper delivery of multilingual education, due to either differing teachers' or learners' perceptions of education needs. Teachers should express respect for the languages, cultures and identities the learners bring into the classroom (Cummins, 2000; Babaci-Wilhite, 2015b). In classrooms, experiences of new language and culture complexities arise for both teachers and learners. In this context, Evans and Cleghorn (2012: 10) aptly coined a term they called "border-crossing", defined as the '...ability to shift conceptually as well as culturally...from one particular way of looking at and understanding the world.' Then, they applied the concept on multilingual education environments, emphasising it is imperative for teachers and learners to cross these borders reciprocally to accommodate the new educational requirements they might come across and negotiate with. Theoretically, the role of the teacher as a facilitator in crossing cultural borders becomes vital for adjusting the requirements of her/his learners in new teaching cultures. Practically, however, teachers can be constrained by their language ideologies to accommodate the culture-bound barriers (Palmer, 2011).

\subsection{Multilingual Education in Africa}

Multilingual education in practice is hardly a consensual reality in Africa and is not even next to reality in Sudan. At 
the time most African countries gained independence, only $43 \%$ of them were using local languages in primary education, while at the beginning of the $21^{\text {st }}$ century, $81 \%$ were so doing (Albaugh, 2007). Ethiopia, Eritrea, Malawi, Somalia, Tanzania, Burundi, Rwanda and the Central Republic of Africa are among the countries pioneered in the integration of local languages into their curricula (Spolsky, 2004). South Africa officialised eleven local languages (Evans and Cleghorn, 2012), making it the first African state to officialise the largest number of native languages. However, neither are the increase in figures of population receiving education in mother tongue nor the growth in the number of countries promoting and/or standardising local languages indicative of a meaningful progress in bridging multilingualism from theory to practice, not the least in employing language to create politically unified states. Africa is still in limbo in this field. The "one language for unity" deficit is perfectly exemplified in Somalia, the only African state with a single native official language, but has been a failed state since 1991. Sudan is another perfect example where Arabic was empowered as a single medium of instruction for the sake of an Arabised/unified Sudan (Sharkey, 2007); yet the ideology did not prevent it from being devastated by protracted ideological and language-related conflicts for over sixty years until South Sudan seceded in 2011.

\subsection{Language Policies in Sudan}

Language policies in Sudan are crudely traceable over two distinct periods - the British colonial and the post-colonial eras. During the British era, the Juba Conference of 1947 was a historical juncture which set overarching benchmarks for the suppression of Arabic for purely colonial and religious reasons (Abu-Manga and Abubaker, 2006). During the post-colonial regimes, however, a notable shift towards policies favouring native languages occurred in 1969 when minority languages were recognised as national languages, and in 1972 when they were given a status, albeit theoretically, equal to Arabic.

While in many African countries language policies embraced in the post-colonial regimes appeared to be a reactionist to the pre-colonial practices (Babacie-Wilhite, 2015b), it does not seem to be the same practice in Sudan, for Arabic - which is not a native language - was officialised to spearhead the fight against both the colonial linguistic hegemony and the powerless native languages (Abdelhay et al. 2012). Pioneered by successive Arab-dominant regimes, the ideology of Islamising and Arabising Sudan was factored into conflating Arabic and Islam as inseparable components in the making of Sudan's identity and culture (Sharkey, 2007). In 1989, another significant language policy was adopted. The government established the National Assembly for Language Planning and commissioned it to (a) strategise for language planning; (b) promote the spread of Arabic as the language of wider communication; and (c) empower Arabic to lead the economic, social and political development of the country. Consequently, Arabic was made the single medium of instruction from the primary education, which has been in effect since 1956 throughout the tertiary level which started in 1990. The year 2005 marked another juncture in the language policies in Sudan, for the right to use the former south Sudan local languages in teaching in primary schools was incorporated into the Comprehensive Peace Agreement which was reached in Naivasha, Kenya, in 2005.

In the contexts of prevailing language policies suppressive to native languages as such, we argue, the dilemma of native languages in Darfur must have been perpetuated by a deliberate state-geared policy for disenfranchising LMS who were displaced by the current conflict. For that, multilingualism was one of the demands negotiated in the Darfur Peace Agreement which was concluded in 2006 in Abuja, Nigeria, and the subsequent peace agreement reached in Doha, Qatar, 2011.Theoretically, minority linguistic rights were enshrined in both agreements, but the right to receiving instruction in mother was not constituted; nor was there either protocol in the agreements for practically accommodating native languages at the national curricula development circles.

\subsection{Darfur: People, Languages and Conflict}

Composed of five states, Darfur is located in the western part of Sudan, with an area of 549,000 square kilometres and, based on 2008 census, a population of 7,405,231. The complexion of the vast majority of the Darfuris renders them Africans; but when identification with ethnic origins is indexed, they are classifiable into unmistakably two distinct groups - Arabs and the Blacks; the latter is often pejoratively referred to by the former as zurga, literally meaning the Blacks (Harir, 1993).

According to the 1953 census, out of the 16 languages spoken by $45 \%$ of the population in Darfur, Arabic was spoken by $55 \%$. But no census-extracted statistics are available on the number of Arabic or native language speakers since then. Today, many native language speakers are characterised by ethnolinguistic vitality and vigorously speak their languages (Garri and Mugaddam, 2015) at wide everyday communication domains. However, Arabic is the single official language and is widely spoken in Darfur by almost all the population in varieties greatly different from that spoken in central Sudan. 
From colonial times to the present day, Darfur has experienced protracted ethnic conflicts. In 2003, however, one of the most heinous conflicts ever known in its contemporary history erupted. An armed movement named itself the Sudan Liberation Movement/Army emerged, later broken up into ever-mushrooming splinter groups, and declared war against the government. In response, the government recruited infamous paramilitary militias known as Janjaweed to fight the armed movements. By February 2014, thousands of African civilians of ethnic origins were either killed, internally displaced or forced to take refuge in neighbouring countries. Many UN sources reported that the conflict claimed between 200,000 and 500,000 lives, about 2000 villages were completely decimated and more than two million people were made homeless (Garri, 2015). The latest official UN Resolution (2363) of June 2017 estimates the number of IDPs in Darfur to 2.7 million, of which 2.1 million are in need of humanitarian assistance.

As Reid (2006) notes, schools in Darfur are understaffed, under-funded and often located in remote and hardly accessible areas. Our field observation suggests that one can coin countless 'under-' words to describe the deplorable situation of schools the IDPs' children were studying at. Among the estimated 257,000 conflict-affected children of school age in South Darfur State alone, two-thirds of them were IDPs (ibid.).

\section{Methodology}

\subsection{Population and Sample}

The population of this study comprised 6,400 IDPs schoolchildren studying in grade-two in twenty basic schools (equivalent to primary schools) located at Kalma, Direig and Otash IDPs camps, and in one school in Nyala town the capital of South Darfur State. The population also comprised 400 teachers who were teaching the first and second grades at the aforesaid schools as well as parents from the same camps. Kalma camp is about 17 kilometres to the south-east of Nyala town whereas Direig and Otash camps are, respectively, in the eastern and northern outskirts of Nyala. As of October 2017, statistics we obtained from UNHCR Office in Nyala estimated there were 253,752 IDPs, out of 528,833 IDPs in South Darfur State, who were displaced to the three camps at intermittent intervals since the eruption of the conflict in 2003.

We identified three samples; the first one comprised 324 schoolchildren divided into two groups: a group of 201 children who were studying at a school at Kalma camp (hereinafter referred to as School A) representing - besides other small ethnic groups - Fur, Zaghawa, Masalit and Daju ethnic groups. The former three ethnic groups spoke their native languages widely at the camps and in various domains whereas the latter group's language was spoken only limitedly by elders. The other group comprised 123 schoolchildren who were studying at a school in Nyala (hereinafter referred to as School B). Both samples were administered Arabic proficiency tests. The second sample included 105 teachers who were teaching at the targeted schools and responded to a questionnaire. The third sample, comprised 27 persons, including 17 graduate teachers with experiences ranged between 5 to 25 years and 10 parents. All the parents were either Fur, Zaghawa and Masalit who spoke - besides Arabic - their native languages or Daju and Borno ethnic groups who were remarkably shifting to Arabic. All the teachers at Kalma camp were Fur and spoke the Fur language. However, the teachers at the other schools were of mixed ethnic origins who spoke, besides Arabic, their mother tongues or Arabs who exclusively spoke Arabic. As it is the instructional requirement across Sudan, and regardless of their ethnic origins, the teachers had to use semi-classical Arabic dialect as a medium of instruction.

School (A) was selected to exemplify a sample of LMS who were displaced from rural areas where a variety of broken Arabic was spoken and, hence, were hypothesised as academically disadvantaged because of their low proficiency in Arabic. School (B) exemplified a sample of schoolchildren who were never displaced and were proficient in Arabic; and thus they were hypothesised as academically privileged, for language was not a communication barrier for them. The latter sample also represented children of different ethnic groups whose languages were widely spoken in their homelands, but were proficient bilinguals as well. The rationale for selecting these two schools was to compare the level of (under)achievement between the two samples.

While the quantitative data were collected during the academic year 2013/2014, the qualitative data were being gleaned ever since throughout October 2017.

To investigate learning difficulties of the IDPs schoolchildren, we formulated these hypotheses:

1. Giving instruction in Arabic only resulted in the academic underachievement and ineffective classroom interaction among the LMS at the IDPs camps.

2. Learning difficulties of the LMS at the IDPs camps were exacerbated by textbooks designed insensitively to the children's own experiences, identities and cultures. 
3. The current conflict in Darfur created among parents antipathy towards Arabic, the sole language of instruction.

\subsection{Data Collection Tools and Procedures}

We employed a questionnaire to generate the relevant data. It was developed in such a way it would produce data about the levels of (a) schoolchildren's communication difficulties arising from teaching in Arabic only; (b) their overall academic underachievement arising from teaching in Arabic only; and (c) the extent to which representation of the children's cultural realities and identities were underrepresented in the first- and second-grade textbooks, which we hypothesised ultimately contributed to their overall underachievement. We administered the questionnaires to the teachers during the school working hours, and were recovered once completed at the teachers' convenience, spanning from three to four weeks. We also administered an Arabic language proficiency test to grade-two schoolchildren. It was developed to explore their reading and comprehension abilities, how rich or poor they were in vocabulary and writing skills. The test was designed in accordance with the national test templates (refereed by relevant inspectors) which were used to examine the skills thereof for schoolchildren at the same age group investigated in this study. The test was administered by teachers who we had commissioned to invigilate in our presence.

To corroborate the overall performances of the two schools, we examined the same test takers' end-of-year examination records. We also generated additional qualitative data from open-ended ethnographic interviews conducted with the teachers and parents individually at different times at schools or at their respective homes, and by appraising the second-grade textbooks (Arabic Language, Islamic Education and Maths).

The same questions contained in the questionnaire were used for conducting the open-ended interviews with the teachers and parents. After getting the teachers' consent, participant observation was also done while the teachers were teaching the identified classes. A checklist was used for quantifying the effectiveness of teacher-learner communication and the children's level of response to and involvement in classroom activities.

For ease of reference throughout the paper, we coded the extracts from the interviewees' answers: the initials $\mathbf{P}$ and T stand for 'Parent' or 'Teacher'; K, $\mathbf{O}$ and $\mathbf{N}$ stand for 'Kalma camp', 'Otash camp' or 'Nyala town', respectively; and the digits indicate the order of the interviewees in our list. Thus, for example, (OT12) means an extract from a teacher interviewee from Otash IDPs camp, identified as number 12.

As is the case at the IDPs camps across Darfur, there used to be a huge presence of national and international relief organizations at the three camps, in particular the UN-African Union Hybrid Operation in Darfur (UNAMID) which since its inception in 2007 had presence at the three camps for protection purposes. Currently, UNICEF in particular provided limited quantities of school materials for the IDPs schoolchildren. Other NGOs also provide insufficient health services, non-food items and constructed makeshift schools, for the government did not allow them to construct permanent buildings. WFP is the single agency which has unceasingly been providing food for the IDPs, though nowadays in insufficient rations. At the time we embarked on our field visits, access to the camps was restricted except for authorised persons. Accordingly, we obtained an access permission from the IDPs Administrative Unit in the Ministry of Education in Nyala town, South Darfur State, to reach the population of the study. Nowadays, the access is open for the nationals and UNAMID peacekeepers but not for foreign relief workers.

\section{Data Analysis}

\subsection{Classroom Communication and Academic Underachievement}

Our hypothesis in this section held that academic underachievement of the IDPs schoolchildren had resulted from giving instruction in Arabic only which, as a consequent, created ineffective teacher-learner communication breakdowns for the schoolchildren who were less proficient in Arabic because they originally came from communities speaking their native languages. To test this hypothesis, we administered a questionnaire to the teachers of first- and second-grade children at schools in Kalma, Otash and Direig IDPs camps. The teachers were asked to state, firstly, if they (dis)agreed that the children had the aforesaid communication difficulties due to using Arabic as the sole medium of instruction.

Table 1. Do You (Dis)agree That Teaching in Arabic only Arises Communication Difficulties?

\begin{tabular}{lllllll}
\hline & Strongly disagree & Disagree & Uncertain & Agree & Strongly agree & Total $\%$ \\
\hline Count $\%$ & $10.5 \%$ & $19.0 \%$ & $2.9 \%$ & $46.7 \%$ & $21.0 \%$ & $100 \%$ \\
\hline
\end{tabular}


Table (1) shows $46.7 \%$ and $21 \%$ of the teachers, respectively, agreed and strongly agreed that the schoolchildren encountered communication difficulties because they were taught in Arabic only.

Table 2. Do You (Dis)agree That Teaching in Arabic only Causes Academic Underachievement?

\begin{tabular}{lllllll}
\hline & Strongly disagree & Disagree & Uncertain & Agree & Strongly agree & Total \% \\
\hline Count $\%$ & $7.6 \%$ & $4.8 \%$ & $1.9 \%$ & $30.5 \%$ & $55.2 \%$ & $100 \%$ \\
\hline
\end{tabular}

Secondly, the teachers were asked to state if they (dis)agreed that the schoolchildren's overall academic underachievement had to do with the fact they were solely taught in Arabic. As shown in (Table 2), more than a half $(55.2 \%)$ of the teachers and a great number of them (30.5\%) strongly agreed and agreed that, respectively, academic underachievement of the IDPs schoolchildren had resulted from giving instruction in Arabic only.

To corroborate the extent to which giving instruction in Arabic only was responsible for the academic underachievement of the schoolchildren as well, we further administered to the children studying at Schools (A) and (B) tests in 'reading and comprehension in Arabic', 'Arabic vocabulary stock' and their ability to 'write short sentences' (Table 3). The reading comprehension test showed that the overwhelming majority of the children at School (A) failed in the comprehension test (as many as 84.6\%). By contrast, all the children in school (B) passed in the test; and almost a half of them (51.2\%) excelled in the test and (35.8\%) of them did it very well.

Table 3. The Comprehension Test Performance

\begin{tabular}{|c|c|c|c|c|c|c|c|c|}
\hline Marks & \multicolumn{2}{|c|}{$0-14$} & \multicolumn{2}{|c|}{$15-25$} & \multicolumn{2}{|c|}{$21-30$} & \multicolumn{2}{|c|}{ Total counts } \\
\hline School (A) & 170 & $84.6 \%$ & 31 & $15.4 \%$ & $0.0 \%$ & $0.0 \%$ & 201 & $100 \%$ \\
\hline School (B) & 16 & $13.0 \%$ & 44 & $35.8 \%$ & 63 & $51.2 \%$ & 123 & $100 \%$ \\
\hline$*$ Total marks $=30$ & \multicolumn{8}{|c|}{$*$ Minimum marks to pass $=15$} \\
\hline
\end{tabular}

During the test, we also observed that the children at School (B) immediately began reading the passage and then answered the comprehension questions. When the test sheets were distributed to the children at School (A), however, no single child started reading the passage from the outset. Most of them not only waited until the invigilator verbally instructed them to answer the questions, sometimes in their mother tongues, but they also kept on coaxing the teacher into reading for them the whole passage and the comprehension questions.

Table 4. The Vocabulary Test Performance

\begin{tabular}{|c|c|c|c|c|c|c|c|c|c|c|}
\hline Marks & \multicolumn{2}{|c|}{$0-10$} & \multicolumn{2}{|c|}{$11-20$} & \multicolumn{2}{|c|}{$21-30$} & \multicolumn{2}{|c|}{$31-42$} & \multicolumn{2}{|c|}{ Total count } \\
\hline School (A) & 182 & $90.5 \%$ & 19 & $9.5 \%$ & $0.0 \%$ & $0.0 \%$ & $0.0 \%$ & $0.0 \%$ & 201 & $100 \%$ \\
\hline School (B) & 18 & $9.8 \%$ & 10 & $8.1 \%$ & 22 & $17.9 \%$ & 89 & $64.2 \%$ & 139 & $100 \%$ \\
\hline$*$ Total marks $=50$ & \multicolumn{10}{|c|}{$*$ Minimum marks to pass $=21$} \\
\hline
\end{tabular}

The vocabulary test revealed a great variation in the vocabulary stocks of the children at both schools. None of the children at School (A) passed in the test, whereas all of their peers at School (B) passed (Table 4). The vocabulary stock among the IDPs children was almost next to non-existent. The figures in this table are self-explanatory; they clearly depict the learning plight of the IDPs schoolchildren. Arabic vocabulary was their weakest language aspect in all of the test questions they were administered.

Table 5. The Short Sentence Writing Test Performance

\begin{tabular}{lcccccccc}
\hline Marks & \multicolumn{2}{c}{$0-13$} & \multicolumn{2}{c}{$14-20$} & \multicolumn{2}{c}{$21-28$} & Total count \\
\hline School (A) & 149 & $74.1 \%$ & 52 & $25.9 \%$ & $0.0 \%$ & $0.0 \%$ & 201 & $100 \%$ \\
School (B) & 15 & $12.2 \%$ & 54 & $43.9 \%$ & 54 & $43.9 \%$ & 123 & $100 \%$ \\
$*$ Total marks $=30$ & \multicolumn{7}{c}{$* \begin{array}{c}* \\
\text { Minimum pass marks }=14\end{array}$} \\
\hline
\end{tabular}

The sentence writing test further showed that all of the children at School (A) failed in the short sentence writing part, whereas all of their peers at School (B) passed in the same test (Table 5). 
Table 6. Overall Academic Performance in Four Subjects

\begin{tabular}{|c|c|c|c|c|c|c|c|c|}
\hline \multirow{2}{*}{$\frac{\text { Subjects }}{\text { Status }}$} & \multicolumn{2}{|c|}{ Qur'an } & \multicolumn{2}{|c|}{ Islamic Education } & \multicolumn{2}{|c|}{ Mathematics } & \multicolumn{2}{|c|}{ Arabic language } \\
\hline & Passed & Failed & Passed & Failed & Passed & Failed & Passed & Failed \\
\hline School (A) & $32.8 \%$ & $67.2 \%$ & $69.8 \%$ & $30.2 \%$ & $29.8 \%$ & $70.2 \%$ & $43.4 \%$ & $56.6 \%$ \\
\hline School (B) & $100 \%$ & $0.0 \%$ & $100 \%$ & $0.0 \%$ & $100 \%$ & $0.0 \%$ & $100 \%$ & $0.0 \%$ \\
\hline \multicolumn{3}{|c|}{$* \quad$ Total marks for each subject $=100$} & \multicolumn{4}{|c|}{$*$ Pass mark each subject $=50$} & & \\
\hline
\end{tabular}

Finally, we accessed records of the second-grade final exams in the four subjects in which the children were tested (the Holy Qur'an, Islamic Education, Mathematics and Arabic language) to compare the overall academic achievement of the children at both schools (Table 6). Again, the figures were self-explanatory. Apart from their scores in Islamic Education, in which the children at School (A) managed to pass (69.8\%), their overall achievement in the other subjects was extremely low. On the contrary, all of the children at School (B) passed in all the four subjects.

Findings from the interviews with teachers supported the above findings. Most of the teachers emphasised that giving instruction in Arabic was a factor in the findings thereof, for the level of Arabic proficiency among the children was low enough to hinder them, to an alarming extent, from learning effectively. A teacher (TO12) stated that the IDPs schoolchildren were not as good as their peers in Nyala in communication skills, for almost all the children in the IDPs camps were not fluent in Arabic. For some teachers, the situation of the children who spoke little Arabic was very critical. One teacher deplored the lack of motivation for learning among his classes due to communication barriers, particularly among children in the first grade (TK20). Such lack of interest was, as we also observed, mostly associated with the low interaction on the part of the children.

We also observed that some teachers translated whole lesson chunks into the children's mother tongues to mitigate communication breakdowns. One teacher contended that when he sometimes had to translate into the learners' mother tongue while teaching, his classes seemed to perform better (TK23). It was further argued by one headmaster at Direig camp that "not using the mother tongue jeopardised the credibility of the educational policy" (TD8). Another teacher argued, based on his own experience, children virtually developed proficiency in Arabic through the translation that took place in classrooms (TD16).

In search of workable teaching techniques in such a context, some teachers who spoke local languages code-switched in classes. At School (A), a teacher from the Fur ethnic group informed us he usually shifted to the Fur language to illustrate some points to children of the Fur origin. He added that some of his colleagues often code-switched too to the learners' mother tongues to help them understand lessons better. In the same vein, a teacher poignantly argued that teaching in Arabic was ineffective, for ' ...the majority of the children arrive at schools with very little Arabic' (TO9). The poignancy of vocabulary deficit thesis was further reiterated by many teachers and parents. A parent attributed the learning disability of her ten-year-old daughter to her limited Arabic vocabulary. This argument was again buttressed by another Arabic teacher (TD4): the schoolchildren, he explained, were often hesitant to take part in classroom activities because they feared of being ridiculed by peers for their poor vocabulary. To retain their self-esteem, the teacher said some children remained silent almost all the school day.

However, views varied among the teachers on whether or not it was an ideal practice to use Arabic only or combined with local languages by means of translation and code-switching. A great number of the teachers believed translating texts to reduce mutual communication breakdowns resulted in boring teaching practices as the teachers were unable to transmit ideas appropriately without using a common medium of instruction, i.e. Arabic (PK4). Similarly, a teacher contended that teaching in Arabic did not only facilitate effective two-way communication between teachers and children, but further created active interaction environments, making the majority of the classes more involved in classroom activities (TD18). Another teacher argued that intensive use of the children's first language in the classroom would reduce their opportunities for improving communication skills and also prevent them from becoming proficient in Arabic; hence if a language other than Arabic was used, which was not economical because not all the teachers spoke the native languages, another problem would be created for speakers of other languages (TO15 and TK1).

\subsection{Curriculum and Cultural Background of the IDPs' Children}

This section investigates our hypothesis that learning difficulties of the IDPs' schoolchildren were exacerbated by textbooks designed insensitively to the children's own experiences and cultures, thus exposing them to cultural alienation and social detachment, which ultimately rendered them educationally disadvantaged. The teachers were asked to scale in the questionnaire the extent to which they believed ethno-cultural backgrounds and identities of the 
IDPs children were incorporated into the textbooks.

Table 7. Do You (Dis)agree That the Children's Cultural Realities and Identities are Represented in Curricula?

\begin{tabular}{lllllll}
\hline & Strongly disagree & Disagree & Uncertain & Agree & Strongly agree & Total \% \\
\hline Count $\%$ & $30.5 \%$ & $10.5 \%$ & $9.5 \%$ & $5.7 \%$ & $43.8 \%$ & $100 \%$ \\
\hline
\end{tabular}

Table 7 shows that $30.5 \%$ of the teachers strongly disagreed and $10.5 \%$ of them disagreed that textbooks were designed to reflect cultural realities and identities of the children. On the contrary, $(43.8 \%)$ of the teachers strongly agreed that cultural experiences of the children were represented in the curricula.

The data gleaned from the teacher interviewees revealed that a sizeable number of them were against developing bilingual textbooks or integrating local cultures and identities into curricula for religious viewpoints. In this regard, one teacher argued (TN5):

Arabic is the language of the Qur'an; it should mould the culture of the Muslims. Therefore, there is no need to have all other local languages and cultures included in the curriculum.

To the contrary, another teacher contended that ignoring local cultures and identities in curricula development is a crime, a point which he described it as "... a blatant linguistic and cultural discrimination against non-Arab ethnicities [children]," (TK2).

We also appraised the second-grade textbooks of Arabic Language, Islamic Education and Mathematics (numeracy) to quantify the responsiveness of the textbook contents to the children's surrounding world, as presented through pictorial objects and characters accompanying the thematic contents of each lesson. However, the texts and their ultimate national educational goals as developed in the textbooks were not appraised. Apart from the picturesque objects of different common items and sceneries which were somehow satisfactorily representative of local ones, the three textbooks underrepresented the children's identities. Indicative to this disadvantage is the extensive use of pictures of people (boys, girls, parents, women and men) characterising the stereotypical complexion of the people in central Sudan, presumably an Arab/Arabised person with a light-coloured skin, kinky-like or curly hair. Out of the 244 pictures in the three textbooks characterising teacher-pupil classroom activities, family gatherings, sporting and farming activities, and spiritual performances, only $13.9 \%$ of them characterised the children's own physical features, the true African Negroid features.

\subsection{Parents' Attitudes towards Arabic}

This section tests our hypothesis that the current conflict in Darfur created among parents antipathy towards teaching in Arabic, and that this antipathy vitalised the parents' rejection on their children having been taught solely in Arabic. Again, we conducted open-ended ethnographic interviews to glean the relevant data from parents. They were asked about their perceptions of using Arabic as the sole medium of instruction, and whether this had to do with the underachievement of their children.

The majority of the parents believed their children were underprivileged at schools because of their low fluency in Arabic compared with their peers in Nyala. For example, a parent who was a member of a Parental Council at Kalma camp had this to say (PK26):

If our children should receive the same type of education as those in Nyala do, they should be taught in their own languages.... I wonder why the teachers do not speak to our children in their languages. Every day I force on my child to go to the school. .... [but] he says he can't understand well what the teachers say [in Arabic].

Some parents were afraid of their personal past unsuccessful schooling experiences could be replicated with their children. One parent recollected his schooldays, saying "The only problem that threw me out of the school [made me a dropout] was Arabic and now I feel [see] the tragedy is being repeated with my children," (PD22). In the same vain, another parent contended that teaching in Arabic only was unfair because "...it impedes interaction in the classroom. Even our limited-Arabic children know their peers who are good in Arabic understand lessons better than them," (PK14).

The parents' concerns over the lag of their children in education could not merely be attributed to the choice of medium of instruction, but rather to - and most likely - the emergence of zurga versus Arab dichotomies, which the parents factored both into the current conflict and the unfavourable educational situations created thereof. Pointing out to such a factor, one parent argued that since the beginning of the conflict, one parent argued, "...only the Africans have be displaced. There must be a hidden policy towards displacing us to ...let us forget [lose] our 
languages and deprive our children of receiving good education," (PO7).

Again, our overall observation of the ethnic 'non-Arab versus Arab' divisions the communities created in association with the current conflict diluted the halo given to Arabic for centuries in Darfur. Thus, the negative attitudes the vast majority of the parents' held towards Arabic is attributable to the Arab versus non-Arab antagonisms emerged in the context of the current conflict. In this respect, one parent argued: "Arabic is the language of Arabs who killed and displaced us.... we must abandon it [Arabic]" (PD13). However, the positive attitudes - though mildly - the parents held towards Arabic were more to do with socioeconomic and career mobility factors. Arguing over the instrumental role of Arabic in Sudan, a parent (PO10) argued: "We cannot remove Arabic from our lives because it is a part of our life. We all have to speak in Arabic at schools and at markets. Our children have to learn in Arabic."

\section{Discussion}

The findings conveyed multi-layered educational, sociocultural and ethnic factors that were at play. The academic underachievement of the IDPs' schoolchildren was primarily found to be traceable to teacher-learner communication breakdowns which resulted from the use of Arabic as a sole medium of instruction. The communication breakdowns occurred inevitably as Arabic was not the mother tongue for the vast majority of IDPs children. Most of them were displaced from areas where Arabic was not widely used in everyday communication. As Holmes (2009) notes, a child's communication is developed through multiple cultural factors such as family, socioeconomic status, dialect, and education - all of which can impact his or her education. At the time the children at the same age in the present study were used to be enrolled at schools in their homelands before the eruption of the conflict, their learning difficulties were greatly facilitated by their unhindered contact with peers who spoke Arabic. By February 2014, those who were displaced were almost exclusively natives of African origins characterised by ethnolinguistic vitality (Garri and Mugaddam, 2015); hence, the wide-scale exposure of their children to Arabic-speaking peers as used to be before the conflict was no longer possible.

That teacher-learner communication difficulties arising from giving instruction in a language other than the learner's mother tongue can result in academic underachievement is a well-documented phenomenon (Evans and Cleghorn, 2012). Communication difficulties among the IDPs' schoolchildren must have resulted not only from the children having been taught in Arabic only, but also from, as Cummins (2000) argues, because of being detached from their social and cultural environments. The fact that Arabic is the official, the unrivalled language and a lingua franca suggest that the children should have found no difficulty in speaking in Arabic, but this did not mitigate their communication plight. There are several distinct inter- and intra-communal dialects of Arabic spoken in Darfur which greatly differ from the classical Arabic in which textbooks are written and teaching aids produced. Inside classrooms, we observed, classical or near-classical Arabic was the dominant medium of instruction, whereas in everyday life communications, the children extensively used their mother tongues and/or an Arabic dialect whose intelligibility continuum was largely confined to Darfur and was often pejoratively known as arabi mukassar, literally means a broken Arabic.

Difficulties in reading and writing (as suggested by comprehension, vocabulary and short sentence writing tests) depict the most tangible evidence of academic the underachievement arising from monolingual deficiency. The children were handicapped by the provision of instruction in Arabic only at such an alarming magnitude that their academic career was threatened by total failure. During the tests, the IDPs' children were observed as distracted and unconfident, unlike their peers in Nyala. The test anxiety among the former group must have been increased by their inability to understand the test instructions written in Arabic.

The vocabulary test indicated how the vocabulary stock of the children was one of their weakest language aspects. The weakness to such an alarming degree, however, needs to be further deciphered in future studies. As a rule of thumb, the deficiencies in communication and limited vocabulary have an interrelated effect upon each other. Holmes (2009) maintains that some topics require background knowledge and specialised vocabulary to understand. For example, for someone who is not proficient in English, Holmes explains, the phrase 'stealing a base' in baseball would mean a thief is running away with a 'base', though this has another meaning in English. The IDP children must have frequently suffered from similar instances while learning.

It appears that concerns of the parents over the academic underachievement of their children did not only come from their awareness of the shortcomings resulting from monolingual education and how it could hamper the education of their children. Rather, their views - besides the conflict factor as the parents perceived it below - centred on the overall learning difficulties at the camps, the deplorable physical learning environments the displacement had produced, the passive role of the government in redressing education inequalities and the lack of teaching aids. 
Parents can play a vital role in ensuring the efficiency of multilingual education, but at the IDPs camps this role was nowhere to be realised. There was no direct parent-government collaboration to address such needs, and if any, it could not be effective because the vast majority of the parents were illiterate and were not involved in decision-making in any meaningful manner.

Teachers, however, appeared to be more accommodating than parents in regard to the state-established policy of using Arabic as a single medium of instruction, but were more worried than the parents about their inability to give instruction in local languages, which rendered learning outputs insignificant.

The IDPs children lacked motivation to learn to the extent that, as one parent complained, his son was always unwilling to go to school every day because of his limited Arabic (see extract PK26). Given the possibility of recurrences of absenteeism for such reasons among other children, it would not be a far-fetched conclusion for parents to primarily attribute the academic underachievement of their children to teaching in Arabic.

The plight of the children under the study was not only perpetuated by lack of monolingual education, but also by being alienated from their inherent cultures which could have facilitated, if appropriately employed in instruction (Holmes, 2008), their perception of the world around them. As such, our paper forwards answers to Cummins' (2000: 34) question: "Why is it that underachievement tends to characterize social groups that have experienced long-term devaluation of their identities in the broader society [USA]...?" When children are denied of their identities in hostile learning environments, their learning would start from a disadvantage; and when their previous views about life and the world, which can be rich sources of learners' cognitive development, are dismissed in education settings, their learning occurs in an experiential vacuum too. Learning environments at the IDPs camps looked like confinements in which the children were kept detached from their languages, their identities and local cultures, which ultimately led to ostensibly an unintended but a deliberate and forceful total immersion in Arabic that the government has longed for over years.

The reason that teacher-learner interaction breakdowns occurred in the classroom due to the children's language deficiency was not conclusive among the teachers. They were divided on whether such breakdowns were caused by giving instruction in Arabic only, techniques teachers could use to overcome it, or probably by other factors the present study is short of to unveil. For the majority of the teachers, the use of the children's mother tongue could not be avoided as a technique to overcome communication breakdowns and, hence, to overcome the problem of academic underachievement. For others, the education dilemmas should be conceived according to the monolingual policy within which the overall academic underachievement issues could be situated and handled. However, our observation also confirms the very obvious communication barrier which occurred because of using Arabic as the only medium of instruction. Code-switching and translation into mother tongue were among the techniques used by some teachers who spoke some local languages. However, such techniques fall short in giving a workable solution, making it a perennial problem for the teachers to overcome the challenges of teacher-learner communication breakdowns to give instruction effectively. In addition, not all teachers were multilinguals, and if some were, the practice was not that efficient.

Again, disagreement among the teachers over the tradition of teaching in mother tongue was obviously a perplexing matter. We ascribe this disagreement to political factors that can, as Evans and Cleghorn (2012) note, hinder teachers from taking into consideration learners' home cultures and languages. Politicised ideologies inform language policies in Sudan (Sharkey, 2007). The teachers in our study apparently had their own ideological or political affiliations, and we discerned some of them were fervent supporters of the government-imposed monolingual education policy whereas proponents of multilingualism were not. Palmer (2011) reached a similar finding in Texas, USA, among teachers of transitional bilingual education programs who supported bilingual education but also employed a discourse that implied 'English dominance' when they came to decide children's transition to English.

Our investigation registered a strong interrelation between academic underachievement of the IDPs schoolchildren and their low proficiency in Arabic. This finding further buttresses the argument that monolingual education is detrimental to bilingual children's academic performance, for language proficiency entails the ability to function at school socially and academically (Cummins, 2000; Baker, 2001; Brisk, 2008).

In addition to the biased and curricula content that is not responsive to linguistic minority students' needs, we also observed that the overall schooling environments were not conducive to promoting learning. Oppressive power relations, in Cummins' terms (2000), existed in the schools. There were no extracurricular activities; nor were there compensatory measures to mainstream the IDPs children. The government left the teachers and children by themselves: the teachers had to invent and apply their own techniques to facilitate teaching and the children to struggle to learn something out of experiential vacuum. 
The teachers' disagreement on whether or not cultural realities of the children were integrated into teaching materials was again a very perplexing finding. We thoroughly appraised the contents of all the four textbooks taught to the population of our study. Apart from the Holy Qur'an textbook in which local cultures had no room to be represented, the contents of the other three textbooks hardly reflected the local cultures, identities or realities of the children. As Curran (2003) and Holmes (2008) argue, using shared commonalities can build the learners' culture and identity in a more inclusive manner, a factor which we found missing in the textbooks. As it was the case with the differing views the teachers posed about using mother tongue to facilitate teacher-learner communication breakdowns, the teachers' contradictory stands about accommodating multiculturalist and multi-ethnic approaches in developing curricula would again depict unmistakable divisions amongst the teachers themselves, which we believe were basically based on their ideological preferences and affiliations rather than about their (dis)agreement on the practicability of multilingualism per se in Sudan. As Sharkey (2007) argues, Arabism and/or Africanism of Sudan are debatable issues, which must have also surfaced among the teachers.

While concerns regarding the inequality arising from monolingual education were overtly voiced by a few teachers, they did not reasonably defend their belief that Arabic, as claimed by few of them, was an indispensable medium of instruction for religious reasons. We believe that viewpoints of the teachers on the interrelation between religion and Arabic are ascribable to the stereotypical perception among some Muslims that Arabic is the language of Islam. This argument is untenable. Millions of Muslims around the world do not know or speak Arabic but are known for their faith in and submission to Islam.

Differences in opinions between teachers and parents in whether the IDPs children should receive instruction in mother tongue further invite us to suggest that the urgency of bilingualism in education is gaining ground among teachers and parents more than ever before. The reasons are not merely linguistic. Amidst the state-led suppression of native languages, simmering undercurrents of linguistic rights awareness have begun to surface among the speech communities in Darfur. As Garri (2013) notes, it was not until 2010 when the emergence of native language revitalisation movements was in full swing in Darfur and, with this, the dormant grievances over linguistic inequalities were focused on and heightened by the current conflict among speech communities in Darfur.

As Albaugh (2007) found in Cameroon and Babaci-Wilhite (2015a) in Tanzania, the finding that parents preferred educating their children in the national language for economic reasons is tenable. In Darfur as well, the belief that Arabic should be used in education for economic reasons was agreed upon by almost all the teachers and few parents. The credit given to Arabic for this reason was apparently associated with Arabicisation, i.e. teaching in Arabic at tertiary level, and in its instrumental role in economic gains. Having a good command of Arabic is a prerequisite for getting a job; and preference of learning in Arabic in this sense would be indisputable as the economic gains are weighed against one criterion, i.e., one should either receive education in Arabic or would miss potential career opportunities. However, the parents' positive attitudes towards Arabic are, though as insignificant as they were, by no means attributable solely to economic reasons. Nor could they be linked to their concerns about instruction in mother tongue. Rather, the current conflict in Darfur seems to have given rise to sentimentality about native languages and the revitalisation of ethnicity and in-group identities. This trend was found to be more ubiquitous among educated parents than among uneducated ones.

It is noteworthy that the findings reached in this study cannot be generalised, at least not in the long term. The IDPs children are currently undergoing a de facto fast pacing linguistic immersion being facilitated by their constant contact with people in towns. Their communication difficulties are not as critical today as they were at the beginning of the displacement. For the long term, teachers and parents will have no choice but to encourage their children to learn in Arabic to cope with the national monolingual policy in education as they cannot resist it indefinitely. Moreover, children raised in the IDPs camps will also not continue to be as disadvantaged at schools as those who were displaced at the beginning of the conflict. The former can overcome their low proficiency in Arabic by their current ongoing wide-scale exposure to exclusively Arabic-speaking communities. Many IDPs (schoolchildren, parents and youth) are now commuters and are becoming resilient by leading in petty trades and small businesses in towns where exposure to exclusively Arabic-speaking communities is unavoidable.

Sudan adopted, in Spolsky's (2004) term, a linguicentric language policy, and accordingly, linguistic rights to multilingual education are denied, except at a theoretical level. Our findings suggest that the IDPs' children were suffering from multi-faceted learning difficulties exacerbated by the absence of their cultural and linguistic heritages at macro language policy-making levels: the state develops curricula that deny the right to receive instruction in mother tongue. A careful selection of an acceptable medium of instruction for linguistic minorities is an important factor, as Babaci-Wilhite (2015) notes, in enriching the learners' cultural, emotional, cognitive and 
socio-psychological benefits, which remains a far-fetched reality in Sudan.

Our study offers some insightful implications. There is an Arabicisation process in Sudan through linguicide and linguicism in the way suggested by Skutnabb-Kangas and Philipson (1995). It has been a state-geared language policy for more than sixty years. Given that the overwhelming majority of the IDPs are characterised by ethnolinguistic vitality, their displacement to camps in the vicinities of many cities in Darfur has exposed them to contact with Arabic-speaking communities at an unprecedented magnitude, both in the length of time and in the intensity of contact. Thus, the loss of native languages becomes increasingly inevitable. For the government, the time is now ripe to invest in this by-product of conflict by intensifying the current coercive assimilation through which the ongoing Arabicisation process can be expedited. As there is no glimmer of hope the conflict in Darfur could be resolved soon and the IDPs could return to their homelands, the collective loss of native languages will be recalled in history as the most intense in magnitude, the largest spacio-temporally and of the most profound sociolinguistic repercussions in both.

There is a reason to believe that the government has deliberately distanced itself from intervention to alleviate the IDPs children's plight. It conceives, in Baker's (2001) terms, the 'sink or swim' approach to monolingual education which is a cost-effective shortcut to the process of native cultural and linguistic erasure. The current policy in practice is, to describe it aptly from the government's implicit perspective, is a 'sink or sink' in approach rather than 'sink or swim'. We remain not only persuaded of the finding that the longer the IDPs stay at the camps, the more quickly they will lose their languages but also the more persistent the government's current policy to erase the native languages, cultures and identities, the more resistant the IDPs will become to the policy in the short and middle run.

Nevertheless, for the teachers at IDPs camps, parents and multilingual education proponents, the case of schoolchildren in Darfur makes it difficult not to realise that multilingual education in Sudan is implausible. Sudan exemplifies, in Kamwangamalu's (2016) term, the 'medium-of-instruction conundrum in Africa. Approximately sixteen local languages are spoken in Darfur, with no single language spoken by any dominant group. Moreover, Sudan is being devastated by several protracted civil conflicts based on political and ethnic rights backgrounds. South Sudan separated from Sudan in 2011 against the backdrop of - among others - socio-political, socioeconomic and linguistic inequalities. The unity of Sudan will again be at stake unless national language policies timely capitalise on the trendy emerging multilingualism approaches that call for recognising minority linguistic rights, or the Sudan-South Sudan political intricacies might be replicated in Darfur.

Our observations finally suggest that the dilemma of the schoolchildren was not entirely about difficulties arising from monolingual education of the conflict itself. Other factors are also at play, including the escalating insecurity situation at the IDPs camps, lack of trained teachers, timely acquisition of textbooks, and the deplorable school environment in which the IDPs children study. Persistence of inequalities in education at the IDPs camps might further produce inevitable grievances that may threaten communal integrity and security. The government may need to balance between the short-term benefits of Arabicisation that it has sought and the bottom-up pressures to have minority linguistic rights practically recognised; otherwise, neglecting the needs of IDPs schoolchildren will continue to reproduce dire social, economic and insecurity disparities in the long term.

\section{Conclusion}

The paper has explored language policies in Africa from a historical perspective. We have argued that while the call for decolonising Africa from linguistic hegemony was an appealing rhetoric to politicians and scholars alike, language policies across the continent have achieved no more than reproducing the colonial ideology of officialising the dominant language at the cost of native languages.

The study has further investigated the extent to which monolingual education, i.e., giving instruction in Arabic only, had an impact on the achievement of the displaced children coming from speech communities in the war-torn Darfur. The study has concluded that giving instruction in Arabic as a single medium of instruction resulted in the IDP's schoolchildren lag in their overall academic achievement. This problem was perpetuated by, on the one hand, their low proficiency in Arabic which resulted from and/or resulted in the lack of efficient classroom teacher-learner interaction and, on the other hand, because the textbooks were designed in a way which was insensitive to their immediate learning needs.

The study has highlighted that multilingual education in Darfur is hardly an achievable goal. Teachers and learners as a consequence have to cope with the plight of IDPs' schoolchildren education arising from such a policy. We have also argued that this conundrum emanates from multi-faceted factors. Bearing in mind the 60 -year long Arabicisation 
policies designed to eliminate the use of native languages, the government is unlikely to adopt multilingual education for the IDPs children. The other factor is the lack of compensatory measures on the part of the government to create environments conducive to quality learning/education even if under monolingual education. Although the conflict is currently not as tense as it from 2003 throughout 2014, the IDPs are unable to return to their homelands for security reasons. Hence, the learning dilemmas of their children will continue to multiply.

\section{References}

Abdelhay, A., Makoni, B., Makoni, S., \& Abdel, R. M. (2012). The sociolinguistics of nationalism in the Sudan: the politicisation of Arabic and the Arabicisation of politics. Current Issues in Language Planning, 12(4), 457-501. https://doi.org/10.1080/14664208.2011.628079

Abu-Manga., Al-Amin., \& Abubaker, Y. (2006). أبو منقة، الأمين ويوسف، أبوبكر 2006. أوضاع اللغة في السودان: [Situations of Language in Sudan: Linguistic Studies]. Khartoum: Khartoum University Press.

Albaugh, E. (2007). Language choice in education: a politics of persuasion. Journal of Modern African Studies, 45(1), 1-32. https://doi.org/10.1017/S0022278X06002266

Babaci-Wilhite, W. (2015a). Language, Development Aid and Human Rights in Education: Curriculum Policies in Africa and Asia. London: Palgrave Macmillan. https://doi.org/10.1057/9781137473196

Babaci-Wilhite, W. (2015b). Local Languages as a Human Right in Education Comparative Cases from Africa. Rotterdam: Sense Publishers. https://doi.org/10.1007/978-94-6209-947-0

Baker, C. (2001). Foundations of Bilingual Education and Bilingualism (3rd ed.). Clevedon: Multilingual Matters.

Brisk, M. (2008). Bilingual Education: From Compensatory to Quality Schooling (2nd ed.). New Jersey: Lawrence Erlbaum Associates, Inc.

Cummins, J. (2000). Language, Power and Pedagogy: Bilingual Children in the Crossfire. Clevedon, UK: Multilingual Matters. https://doi.org/10.21832/9781853596773

Curran, E. (2003). Linguistic Diversity and Classroom Management. Theory into Practice, 42(4), 334-340. https://doi.org/10.1207/s15430421tip4204_11

Evans, R., \& Cleghorn, A. (2012). Complex Classroom Encounters a South African Perspective. Rotterdam: Sense Publishers. https://doi.org/10.1007/978-94-6209-083-5

Garcia, O. (2009). Bilingual Education in the $21^{\text {st }}$ Century: A Global Perspective. Sussex: Wiley-Blackwell.

Garri, D. (2013). Conflict as a factor in the emergence of reversing language attitudes: The case of speech communities in Darfur. Proceedings of the Annual Conference of Postgraduate Studies and Scientific Research, University of Khartoum, 1, 419-437.

Garri, D., \& Mugaddam, A. R. (2015). Language and identity in the context of conflict: the case of ethnolinguistic communities in South Darfur State. The International Journal of the Sociology of Language, 235, 137-167. https://doi.org/10.1515/ijsl-2015-0018

Harir, S. (1993). Racism in Islamic disguise? Retreating nationalism and upsurging ethnicity in Dar Fur, Sudan. In H. Veber (Ed.), Never drink from the same cup: Proceedings of the conference on indigenous peoples of Africa. Copenhagen: International Work Group for Indigenous Affairs. 291-311.

Holmes, J. (2008). Culture and Identity in Rural Africa: Representation through Literacy. Language and Education, 22(6), 363-379. https://doi.org/10.1080/09500780802152747

Holmes, S. (2009). Everything is not What It Seems: Ideologies of racial and ethnic identity in Disney's wizards of Waverly place. Paper presented at the National Communication Association Annual Conference, Chicago.

Kamwangamalu, N. M. (2016). Language Policy and Economics: The Language Question in Africa. Palgrave Studies in Minority Languages and Communities, eBook. https://doi.org/10.1057/978-1-137-31623-3

May, S. (2008). Language and Minority Rights: Ethnicity, Nationalism and Politics of Language. New York: Rutledge.

Mugaddam, A. R. (2006). Small languages and small language communities. International Journal of the Sociology of Language, 181, 123-136. 
Palmer, D. (2011). The Discourse of Transition: Teachers' Language Ideologies within Transitional Bilingual Education Programs. International Multilingual Research Journal, 5, 103-122. https://doi.org/10.1080/19313152.2011.594019

Reid, K. (2006). Right to Education in South Darfur. Forced Migration Review, 26, 60-61.

Sharkey, H. (2007). Arab Identity and Ideology in Sudan: The politics of language, Ethnicity, and Race. African Affairs, 107(426), 21-43. https://doi.org/10.1093/afraf/adm068

Skutnabb-Kangas, T., \& Philipson, R. (1995). Linguicide and linguicism. Rolig Paper 53, Roskilde Universitetscenter. Denmark: 83-91.

Spolsky, Bernard. (2004). Language Policy. Cambridge: Cambridge University Press.

Truong, N. (2012). Language of instruction: Unlocking effectiveness of education and sustainable development in Sub-Saharan Africa. International Education, 42(1), 6-21.

Wolff, H. E. (2017). Language ideologies and the politics of language in post-colonial Africa. Stellenbosch Papers in Linguistics Plus, 51, 1-22. https://doi.org/10.5842/51-0-701

Wright, W., Boun, S., \& Garcia, O. (2015). Introduction: Key concepts and issues in bilingual and multilingual education. In Wayne E. Wright, Sovicheth Boun, and Ofelia Garcia (Eds.), The Handbook of Bilingual and Multilingual Education. Sussex: John Wiley \& Sons. https://doi.org/10.1002/9781118533406 